Research Article

\title{
Benefit of addition of clopidogrel in addition to aspirin and fibrinolytic therapy in STEMI: an Indian data
}

\author{
Abhilash Kannan ${ }^{1}$, Rajasekharan Chandrasekharan ${ }^{2}$, \\ Radhakrishnan Vallikkattu Velayudhan ${ }^{3}$
}

\begin{abstract}
${ }^{1}$ Associate Professor of Medicine, Sree Gokulam Medical College, Thiruvananthapuram, Kerala, India ${ }^{2}$ Professor of Medicine, Government Medical College,

Thiruvananthapuram, Kerala, India ${ }^{3}$ Professor of Cardiology, Government Medical College, Alappuzha, Kerala, India
\end{abstract}

Received: 18 June 2013

Accepted: 28 June 2013

*Correspondence to:

Dr. Abhilash Kannan,

Email:

drabhilashkannan@yahoo.com

(C) 2013 Kannan A et al. This is an open-access article distributed under the terms of the Creative Commons Attribution License, which permits unrestricted use, distribution, and reproduction in any medium, provided the original work is properly cited.

\begin{abstract}
Background: The study was designed to find out whether the addition of clopidogrel for patients with ST- elevation myocardial infarction [STEMI] who are receiving a standard fibrinolytic therapy, including aspirin, reduce the incidence of primary and secondary end points like recurrent ischemia, re-infarction, need for urgent Target Vessel Revascularisation [TVR], mortality \& bleeding.

Methods: The patients were randomly assigned to receive the study medication. The patients were divided into two groups. Those receiving fibrinolytic therapy \& aspirin were included in Group A. Those receiving the study drug in addition to aspirin \& fibrinolytic agent were included in Group B. The study drug was given daily upto 1 month. These patients were assessed during their hospital stay \& followed up for a period of 30 days for end points like recurrent ischemia, re-infarction, need for urgent TVR, bleeding episodes \& mortality.

Results: There was reduction in primary endpoints in group B compared to group A of which only reduction of recurrent ischemia was statistically significant $(26 \%$ vs $2 \%)$. The same pattern of benefit was seen with secondary end points with significant reduction in recurrent ischemia in group B (28\% vs $2 \%)$. Safety end points showed some increased bleeding in group B patients which was statistically insignificant (4\% vs 0 ).

Conclusion: Addition of Clopidogrel to aspirin and fibrinolytic therapy in ST-elevation MI showed a significant reduction in recurrent ischemia during in hospital stay and during the first 30 days. The patients received clopidogrel had less mortality compared to aspirin group. There were only minor bleeding episodes reported with use of clopidogrel.
\end{abstract}

Keywords: STEMI, Aspirin, Clopidogrel, Primary end points, Secondary end points

\section{INTRODUCTION}

Clopidogrel is an adenosine diphosphate receptor antagonist, a class of oral antiplatelet agents that block the P2Y12 component of adenosine diphosphate receptor $\&$ thus inhibit the activation \& aggregation of platelets. Clopidogrel has been shown to prevent death $\&$ ischemic complications in patients with symptomatic atherosclerotic disease, patients who have undergone percutaneous coronary intervention \& patients with unstable angina or MI without ST segment elevation. The addition of clopidogrel has been shown to be beneficial in two multicentric randomized control trials (CLARITYTIMI28 \& COMMIT/CCS-2) in terms of reducing the odds of the composite end point of death from cardiovascular causes, re-infarction, recurrent ischemia leading to urgent revascularization by $20 \% .^{1,2}$ Our study also assessed whether the addition of clopidogrel is beneficial in Indian patients who have MI with ST segment elevation \& who are receiving streptokinase \& aspirin.

\section{METHODS}

This study was a randomized open label prospective case control study conducted in Intensive Coronary Care Unit at a tertiary care centre in Thiruvananthapuram. Sample size was 100 . The patients were randomly assigned into two groups. Randomization was done using Statistical Package for Social Sciences for Windows- version 10. 


\section{Inclusion Criteria}

1. History of ischemic chest discomfort at rest within 12 hours lasting for more than 20 minutes.

2. ST segment elevation of more than $0.1 \mathrm{mV}$ in two or more contiguous leads.

3. New onset Left Bundle Branch Block.

4. Patient who had received Streptokinase.

\section{Exclusion Criteria}

1. Treatment with clopidogrel within 7 days before enrolment.

2. Contraindication to fibrinolytic therapy [Documented stroke, intracranial hemorrhage, intracranial neoplasm].

3. Prior Coronary Artery Bypass Grafting (CABG).

4. Previous history of Coronary Artery Disease (CAD).

5. Patients having cardiogenic shock at the time of admission.

6. Plan to perform angiography within 48 hours in the absence of a new clinical indication.

7. Contraindication to antiplatelets [Aspirin allergy, Thrombocytopenia].

The patients satisfying above criteria were selected and were randomly assigned into the two groups. Patients included in aspirin group (Group A) would receive 325 $\mathrm{mg}$ of aspirin along with fibrinolytic therapy and then followed by $150 \mathrm{mg}$ of aspirin once daily thereafter with other drugs which depend on discretion of treating physician. Patients included in the clopidogrel group (Group B) received $300 \mathrm{mg}$ of clopidogrel in addition to aspirin and fibrinolytic therapy and then followed by $75 \mathrm{mg}$ of clopidogrel daily along with aspirin and other drugs. These patients are assessed during their hospital stay for end points like recurrent ischemia, re-infarction, need for urgent TVR, bleeding episodes and mortality. A thirty day telephonic follow-up was also done to assess the occurrence of the above end points in these patients.

Recurrent ischemia was characterized by appearance of ischemic type of chest pain with or without ECG changes and which showed relief with nitrates. Re-infarction after thrombolytic therapy is based upon recurrence of ischemic type chest pain lasting at least 30 minutes, which may be associated with ST - T changes, and reelevation of Creatinine Phosphokinase (CPK). To diagnose an early re-infarction, an increase of $50 \%$ or more in CPK activity above the preceding base line (mean of the two preceding samples) in at least two samples separated by a minimum of 4 hours within a 24 hours interval. If the CPK activity is on the down slope from the antecedent infarction, a 25\% increase is considered diagnostic. If CPK has returned to normal, a secondary elevation of CPK activity provides for a sensitive and specific diagnosis of re-infarction. Patients who developed episodes of re-infarction were considered for urgent target vessel revascularization and it was done for some of the patients.

Major bleeding was defined as being significantly disabling, intraocular bleeding leading to significant loss of vision, or bleeding requiring transfusion of two or three units of red blood cells or equivalent whole blood. Major bleeding was subclassified as life-threatening or other major bleeding. Life-threatening bleeding complications were defined as fatal or leading to a drop in hemoglobin of $\leq 5 \mathrm{~g} / \mathrm{dL}$ or significant hypotension with the need for inotropes, requiring surgery (other than vascular site repair) or symptomatic intracranial hemorrhage, or requiring transfusion of four or more units of red blood cells or equivalent whole blood. Minor bleeding was defined as any other bleeding requiring modification of drug regimen.

Admission ECGs were taken soon after patient was admitted to the Intensive Coronary Care Unit. Post streptokinase ECGs were taken at 90 minutes after initiation of thrombolytic therapy.

Data were analyzed using computer software, Statistical Package for Social Sciences (SPSS) version 10. Data were expressed in its frequency and percentage. To elucidate the associations and comparisons between different parameters, Chi square $\left(\chi^{2}\right)$ test was used as nonparametric test. Odds ratio was performed to analyze risk of different parameters on outcome. For all statistical evaluations, a two-tailed probability of value, $<0.05$ was considered significant.

The limitations of the study include the non confirmation of patency of the vessel by coronary angiography.

\section{RESULTS}

Of the 100 patients studied 50 patients were included in group A and 50 patients were included in group B. Of the 50 patients included in group A, $4 \%$ belong to the age group of $<40$ years, $82 \%$ belong to the age group of 40 75 years, and $14 \%$ belong to the age group of $\geq 75$ years. Of the 50 patients in group B, $8 \%$ belong to the age group of $<40$ years, $84 \%$ belong to the age group of $40-75$ years, and $8 \%$ belong to the age group of $\geq 75$ years. The mean age of patients in group A is 59.26 and in group B is 55.8. This difference in mean age in the two groups is statistically insignificant $(\mathrm{P}>0.05)$.

Of the 50 patients in group A, $78 \%$ were males and $22 \%$ were females. Of the 50 patients in group B, $84 \%$ were males and $16 \%$ were females. $36 \%$ patients in group A and $42 \%$ patients in group B had hypertension. $64 \%$ patients in group A and 58\% patients in group B did not have hypertension. $26 \%$ of patients in group A and $30 \%$ of patients in group B had diabetes mellitus. $74 \%$ in group A and 70\% group B did not have diabetes mellitus. 
$2 \%$ of the patients in group $\mathrm{A}$ and $8 \%$ of the patients in group B had evidence of other vascular diseases. $98 \%$ of patients in group A and $92 \%$ patients in group B did not have any features of other vascular diseases. $84 \%$ of the patients in group A and $88 \%$ of the patients in group B had dyslipidemia. $16 \%$ of the patients in group $\mathrm{A}$ and $12 \%$ of the patients in group B did not have dyslipidemia. $68 \%$ of the patients in group A and $72 \%$ of the patients in group B were smokers. $32 \%$ of the patients in group A and $28 \%$ of the patients in group B were non-smokers. $22 \%$ of the patients in group A and $16 \%$ of the patients in group B were post-menopausal females. $58 \%$ of patients in group A and $48 \%$ of patients in group B were having anterior wall myocardial infarction. $42 \%$ of patients in group $\mathrm{A}$ and $52 \%$ patients in group B were having myocardial infarction in non-anterior wall territories. All these above differences were statistically insignificant $(\mathrm{P}>0.05)$.

Post-Streptokinase ECG showed a significant change in the study group compared with the control group. <30\% reperfusion was seen in $22 \%$ of patients in group A whereas group B had only $8 \%$ of the patients in this category. $>70 \%$ reperfusion was seen in $54 \%$ of the patients in group B whereas it was present in only $34 \%$ of the patients in group $\mathrm{A}(\chi 2=5.978 ; \mathrm{P}<0.05) .40 \%$ of the patients in group A and $54 \%$ of the patients in group B had a window period $<4$ hours whereas $60 \%$ of the patients in group A and $46 \%$ of the patients in group B had a window period $>4$ hours.

\section{Complications (Table 1)}

$24 \%$ of the patients in group A and $4 \%$ of the patients in group B had features of left ventricular dysfunction. Chi square analysis showed that this difference was statistically highly significant $(\chi 2=10.698 ; \mathrm{P}<0.01)$. $8 \%$ of the patients in group A had complete heart block whereas none in group $\mathrm{B}$ had evidence of complete heart block $(\mathrm{P}>0.05) .6 \%$ of the patients in group A had atrial arrhythmias, but it was absent in group $B$ $(\mathrm{P}>0.05) .2 \%$ of the patients in group $\mathrm{A}$ had cardiogenic shock whereas it was absent in group B $(\mathrm{P}>0.05) .2 \%$ of patients in group A had developed ventricular tachycardia, whereas it was absent in group $\mathrm{B}(\mathrm{P}>0.05)$. $2 \%$ of the people in group $A$ had mechanical complications whereas none was reported in group $\mathrm{B}$ $(\mathrm{P}>0.05) .2 \%$ of the patients in both group $\mathrm{A}$ and group $\mathrm{B}$ had developed features of pericarditis $(\mathrm{P}>0.05)$. In the present study, complications were absent in $66 \%$ of the patients in group A and $94 \%$ in group B. Chi square analysis showed that the decrease in the number of complications in the study group B was significant $(\chi 2=$ 15.783; $\mathrm{P}<0.05)$.

$34 \%$ patients of the patients in group A had to be started on Clopidogrel due to development of recurrent ischemia and other complications. Chi square analysis showed that this crossing over was highly significant $(\chi 2=20.482 ; \mathrm{P}<0.01)$.
Table 1: Complications.

\begin{tabular}{|lll|ll|}
\hline \multirow{2}{*}{ Complications } & \multicolumn{2}{l|}{ Group A } & Group B \\
\cline { 2 - 5 } & Count & Percentage & Count & Percentage \\
\hline LVF & 12 & 24 & 2 & 4 \\
\hline CHB & 4 & 8 & - & - \\
\hline $\begin{array}{l}\text { Atrial } \\
\text { Arrhythmia }\end{array}$ & 3 & 6 & - & - \\
\hline $\begin{array}{l}\text { Cardiogenic } \\
\text { Shock }\end{array}$ & 1 & 2 & - & - \\
\hline VT / VF & 1 & 2 & - & - \\
\hline $\begin{array}{l}\text { Mechanical } \\
\text { Complications }\end{array}$ & 1 & 2 & - & - \\
\hline Pericarditis & 1 & 2 & 1 & 2 \\
\hline None & 33 & 66 & 47 & 94 \\
\hline
\end{tabular}

$(\chi 2=15.783 ; \mathrm{P}<0.05)$

\section{Primary End Points (Table 2)}

$26 \%$ of the patients in group A had recurrent ischemia whereas it was seen in only $2 \%$ of patients in group B. Chi square analysis showed that this difference was highly significant $(\chi 2=11.960 ; \mathrm{P}<0.01) .6 \%$ of the patients in group A had developed re-infarction whereas it was present in only $2 \%$ of the patients in group B. Chi square analysis showed that this difference was insignificant $(\chi 2=1.042 ; \mathrm{P}>0.05)$. Mortality during hospital stay was seen in $10 \%$ of the patients in group A whereas it was present only in $2 \%$ of the patients in group B. Chi square analysis showed that this difference was insignificant $(\chi 2=2.837 ; \mathrm{P}>0.05)$. In the present study, primary end points were absent in $64 \%$ of the patients in group A whereas it was absent in $94 \%$ of the patients in group B. Chi square analysis showed that this difference was statistically highly significant $(\chi 2=14.848 ; \mathrm{P}<$ $0.01)$. Risk for the potential occurrence of primary end points in group A was found to be 4.17 times that of group B (Odds Ratio 4.165).

Table 2: Primary end points.

\begin{tabular}{|lllll|}
\hline \multirow{2}{*}{$\begin{array}{l}\text { Primary } \\
\text { Points }\end{array}$} & \multicolumn{2}{l}{ Group A } & Group B \\
\cline { 2 - 5 } & Count & Percentage & Count & Percentage \\
\hline $\begin{array}{l}\text { Recurrent } \\
\text { Ischemia }\end{array}$ & 13 & 26 & 1 & 2 \\
\hline Re-Infarction & 3 & 6 & 1 & 2 \\
\hline Mortality & 5 & 10 & 1 & 2 \\
\hline None & 32 & 64 & 47 & 94 \\
\hline
\end{tabular}

$(\chi 2=14.848 ; \mathrm{P}<0.01)$ 


\section{Secondary End Points (Table 3)}

$28 \%$ of the patients in group A developed recurrent ischemia whereas it was present only in $2 \%$ of the patients in patients group B. Chi square analysis showed that this difference was very highly significant $(\chi 2=$ 18.279; $\mathrm{P}<0.001) .2 \%$ of the patients in the group $\mathrm{A}$ had the need for urgent target vessel revascularization whereas it was absent in group $\mathrm{B}(\mathrm{P}>0.05)$. In the present study, secondary end points were absent in $72 \%$ of the patients in group A whereas it was absent in $98 \%$ of the patients in group B. Chi square analysis showed that this difference was very highly significant $(\chi 2=16.279$; $\mathrm{P}<$ $0.001)$. There were only $2 \%$ complications in the group $\mathrm{B}$ after 30 day follow up where as group A showed $30 \%$ occurrence during the follow up. Risk for the potential occurrence of secondary end points in group A was found to be 6.34 times that of group B (Odds Ratio 6.34). The risk estimate after 30 days of observation was found to be increased $32.6 \%$ than that of primary end point observation.

Table 3: Secondary end points.

\begin{tabular}{|lllll|}
\hline $\begin{array}{l}\text { Secondary } \\
\text { End } \\
\text { Points }\end{array}$ & \multicolumn{2}{l}{ Group A } & Group B \\
\cline { 2 - 5 } & Count & Percentage & Count & Percentage \\
\hline $\begin{array}{l}\text { Recurrent } \\
\text { Ischemia }\end{array}$ & 14 & 28 & 1 & 2 \\
\hline Urgent TVR & 1 & 2 & - & - \\
\hline None & 36 & 72 & 49 & 98 \\
\hline
\end{tabular}

$(\chi 2=16.279 ; \mathrm{P}<0.001)$

\section{Safety End Points (Table 4)}

In the present study, none of the patients in group A had any bleeding complications whereas minor bleeding episodes were present in $4 \%$ of the patients in group B. Chi square analysis showed this difference was insignificant $(\chi 2=2.041 ; \mathrm{P}>0.05)$.

Table 4: Safety end points.

\begin{tabular}{|lllll|}
\hline $\begin{array}{l}\text { Safety } \\
\text { End } \\
\text { Point }\end{array}$ & \multicolumn{2}{l}{ Group A } & \multicolumn{2}{l|}{ Group B } \\
\cline { 2 - 5 } & Count & Percentage & Count & Percentage \\
\hline No & 50 & 100 & 48 & 96 \\
\hline Yes & - & - & 2 & 4 \\
\hline
\end{tabular}

$(\chi 2=2.041 ; \mathrm{P}>0.05)$

\section{DISCUSSION}

An important treatment strategy in acute coronary syndrome is antiplatelet therapy. Platelet inhibitors affect the properties of blood platelets to aggregate. Aspirin (acetyl salicylic acid) is the anchor drug which inhibits the activity of cyclooxygenase in all body cells. Since platelets do not have a nucleus, cyclooxygenase cannot be formed after the platelets have been in contact with aspirin and the platelets are not able to produce thromboxane $\mathrm{A}_{2}$, the proaggregatory platelet-specific prostaglandin, during its life span (median 8 days), while the other body cells rapidly pick up cyclooxygenase production after contact with aspirin. There is no tolerance with aspirin and there is no rebound effect observed in patients who are on chronic aspirin therapy. ${ }^{3}$ Spontaneous life-threatening bleeding with aspirin is rare. Five important trials performed in the seventies and the eighties showed in patients with acute coronary syndrome a reduction of myocardial infarction and death up to $70 \% .^{4-8}$ Since aspirin is inexpensive, it is very cost effective. Aspirin is a relatively weak antiplatelet agent; it blocks only aggregation in response to stimulation by thromboxane. Its effects can be overcome by other stimuli, particularly thrombin, which is the most powerful stimulus of platelet aggregation. ${ }^{9}$ However; it may have important additional effects on platelet-neutrophil interactions and on inflammation. ${ }^{10}$

Clopidogrel is a thienopyridine derivative that irreversibly inhibits the binding of ADP to its receptor on the platelets by blocking the $\mathrm{P} 2 \mathrm{Y}_{12}$ component of the ADP receptor, thereby preventing the transformation of the glycoprotein IIb/IIIa receptor into its active form. CURE (Clopidogrel in Unstable angina to prevent Recurrent Events Study) trial demonstrated that clopidogrel, when added to aspirin and other standard therapies, is beneficial in patients with acute coronary syndromes irrespective of the dose of aspirin used. Compared with a daily dose of 75 to $100 \mathrm{mg}$ with or without concomitant use of clopidogrel, higher doses of aspirin lead to higher rates of bleeding complications without increasing efficacy. ${ }^{11}$

The present study was based on the benefits of clopidogrel in STEMI shown in the two multicentric randomized controlled trials, the CLARITY TIMI-28 and COMMIT/CCS-2, in terms of reducing the odds of the composite end point of death from cardiovascular causes, re-infarction, recurrent ischemia leading to urgent revascularization by $20 \%$. Our study design was similar to that of CLARITY TIMI-28 trial. Our study results showed a statistically significant reduction on primary and secondary end points in patients in study drug group which was comparable with the results of CLARITY TIMI-28. Our study also demonstrated that, among the components of the primary and secondary end points, maximum benefit was with reduction in occurrence of recurrence ischemia. Another significant finding of our study was the need for starting clopidogrel for the patients in aspirin group because of recurrent ischemia and other complications. The cross over rate was $34 \%$ which was statistically highly significant. Also the patients in the study group showed a statistically 
significant reperfusion in the post thrombolysis ECGs compared to control group. Also the study group showed significant reduction in complication rates, the benefit was maximum with the reduction in occurrence of left ventricular dysfunction. The limitations of the study include the non confirmation of patency of the vessel by coronary angiography.

\section{CONCLUSION}

There was significant reduction in both primary and secondary end points in patients who received clopidogrel. The patients received clopidogrel had less mortality compared to aspirin group. This difference was statistically insignificant. There was a significant reduction in the complications in patients who received clopidogrel. The reduction was maximum for occurrence of left ventricular dysfunction. There were a significant number of cross over of patients from aspirin group to clopidogrel group. There were only minor bleeding episodes reported with use of clopidogrel and this was statistically insignificant. Risk for the potential occurrence of primary end points with Aspirin was found to be 4.17 times that with Clopidogrel (Odds Ratio 4.165). Risk for the potential occurrence of secondary end points with Aspirin was found to be 6.34 times that with Clopidogrel (Odds Ratio 6.34). The risk estimate after 30 days of observation was found to be increased $32.6 \%$ than that of primary end point observation.

\section{ACKNOWLEDGEMENTS}

We are thankful to the Dr. Suresh, Former HOD, Dept. of Cardiology, Medical College, Thiruvananthapuram, for permitting us to conduct the study in the intensive coronary care unit. We are also thankful to all the faculty of Cardiology department for their kind co-operation in conducting the study in their department. We are also thankful to the staff of the coronary care unit in helping us to conduct the study in a very smooth organised manner in between their busy schedule.

\section{Funding: None}

Conflict of Interest: None declared

Ethical approval: The study was approved by the Institutional Ethical Committee

\section{REFERENCES}

1. Sabatine MS, Cannon CP, Gibson CM, LópezSendón JL, Montalescot G, Theroux P, et al. Addition of Clopidogrel to Aspirin \& Fibrinolytic therapy for Myocardial Infarction with ST-segment elevation. N Engl J Med 2005;352:1179-89.

2. Cannon C. Perspective on COMMIT/CCS-2 Trial of Clopidogrel in STEMI. Available at www.clintrialresults.org/Slides/COMMITClopidogr el\%20LBCT\%20Comments\%20-

\%20ACC\%202005.ppt. Accessed 15 March 2013.

3. Pedersen AK, Fitzgerald GA. Dose-related kinetics of aspirin. Presystemic acetylation of platelet cyclooxygenase. N Engl J Med 1984;311:1206-11.

4. Lewis HD, Davis JW, Archibald DG, et al. Protective effects of aspirin against acute myocardial infarction and death in men with unstable angina. N Engl J Med 1983;309:396-403.

5. Cairns JA, Gent M, Singer J, et al. Aspirin, sulfinpyrazone, or both in unstable angina. N Engl J Med 1985;313:1369-75.

6. ISIS-2 (Second International Study of Infarct Survival) Collaborative Group. Randomized trial of intravenous streptokinase, oral aspirin, both, or, neither among 17,187 cases of suspected acute myocardial infarction: ISIS-2. Lancet 1988;2(8607):349-60.

7. Theroux P, Ouimet H, McCans J, et al. Aspirin, heparin, or both to treat acute unstable angina. N Engl J Med 1988;319:1105-11.

8. The RISC Group. Risk of myocardial infarction and death during treatment with low dose aspirin and intravenous heparin in men with unstable coronary artery disease. Lancet 1990;336:827-30.

9. Heras M, Chesebro J, Penny WJ, et al. Effects of thrombin inhibition on the development of acute platelet-thrombus deposition during angioplasty in pigs. Circulation 1989;79:657-65.

10. Ridker PM, Cushman M, Stampfer M, et al. Inflammation, aspirin and the risk of cardiovascular disease in apparently healthy men. N Engl J Med 1997;336:973-9.

11. The Clopidogrel in Unstable Angina to Prevent Recurrent Events Trial Investigators. Effects of clopidogrel in addition to aspirin in patients with acute coronary syndromes without ST-segment elevation. N Engl J Med 2001;345:494-502.

doi:10.5455/2319-2003.ijbcp20130825

Cite this article as: Kannan A, Chandrasekharan R, Velayudhan RV. Benefit of addition of clopidogrel in addition to aspirin and fibrinolytic therapy in STEMI: an Indian data. Int J Basic Clin Pharmacol 2013;2:480-4. 